\title{
Cultura e gestão da segurança no trabalho: uma proposta de modelo
}

\section{Culture e safety management: the proposal of a model}

\author{
Anastacio Pinto Gonçalves Filho' \\ José Célio Silveira Andrade ${ }^{2}$ \\ Marcia Mara de Oliveira Marinho ${ }^{3}$
}

\begin{abstract}
Resumo: O estudo apresentado neste artigo tem por objetivo desenvolver um modelo para identificar o estágio de maturidade da cultura de segurança de uma organização. Muitos pesquisadores consideram que a cultura de segurança pode evoluir na organização passando por diferentes estágios. Uma cultura de segurança em estágio avançado é um fator importante para a prevenção de acidentes e doenças ocupacionais. O trabalho apresenta uma revisão de literatura sobre o tema, abordando conceitos, fatores essenciais e modelos de estágio de maturidade de cultura de segurança. O resultado deste estudo é um modelo que poderá ser utilizado pelas organizações para identificar o estágio de maturidade de sua cultura de segurança. O modelo é uma importante ferramenta gerencial, pois, identificando qual o seu estágio de cultura de segurança, a organização pode adotar medidas para melhorá-la. O modelo proposto define os seguintes estágios de uma cultura de segurança numa organização: patológico, reativo, burocrático, proativo e melhoria contínua. O estágio é definido pelo modo como a organização trata os seguintes fatores, considerados como essenciais para a cultura de segurança: informação, aprendizagem organizacional, envolvimento, comunicação e comprometimento.
\end{abstract}

Palavras-chave: Cultura de segurança. Maturidade de cultura de segurança. Gestão da segurança do trabalho.

\begin{abstract}
This present study investigates/examines the safety culture maturity in organizations. The objective is to propose a model to identify the stage or level of safety culture maturity in organizations. The model is particularly important in management since once the safety culture maturity level is identified the stakeholders can make decisions to improve it. Many researchers agree that safety culture develops through different levels. A high level of safety culture is important for workplace accident prevention. The result of this study is a model that can be used by organizations to identify their safety culture maturity stage. The stages of safety culture maturity identified in this research include pathological, reactive bureaucratic, proactive, and generative stage. The stages are determined based on how the organization deals with safety culture essential characteristics such as information, organizational learning, communication, commitment, and involvement.
\end{abstract}

Keywords: Safety culture. Safety culture maturity. Safety management.

\section{Introdução}

As questões culturais podem, inúmeras vezes, transformar-se em entraves ou obstáculos significativos para as mudanças requeridas quando da implementação do Sistema de Gestão da Segurança do Trabalho (SGST). Portanto, conhecer a maturidade da cultura existente numa empresa é essencial para a formulação de planos de mudanças, quando necessárias.

Uma cultura de segurança estabelecida é crucial para o florescimento, o sucesso e o bom desempenho do SGST (CHOUDHRY; FANG; MOHAMED, 2007;
EK et al., 2007; HUDSON, 2003), pois é num contexto em que existe cultura de segurança que as atitudes e o comportamento dos indivíduos relativos à segurança se desenvolvem e persistem (MEARNS; WHITAKER; FLIN, 2003). É por essa razão que o conceito de cultura de segurança tem recebido larga atenção, pois os sistemas de gestão funcionarão melhor em organizações que tenham desenvolvido uma maturidade da cultura de segurança (HOPKINS, 2005).

\footnotetext{
${ }^{1}$ Superintendência Regional do Trabalho e Emprego/BA, Setor de Saúde e Segurança no Trabalho, Av. Sete de Setembro, 698, Mercês, CEP 40.060-001, Salvador, Bahia, Brasil, E-mail: anastaciofilho@ufba.br

${ }^{2}$ Escola de Administração, Universidade Federal da Bahia, Av. Reitor Miguel Camon, s/n, Vale do Canela, CEP 40.110-100 Salvador, Bahia, Brasil

${ }^{3}$ Departamento de Engenharia Ambiental, Rua Aristides Novis, 2, Federação, CEP 40.110-100 Salvador, Bahia, Brasil

Recebido em 9/10/2011 — Aceito em 1/12/2010
}

Suporte financeiro: Nenhum. 
Em geral, os estudos sobre cultura de segurança têm dois objetivos principais: caracterizar a cultura de segurança e identificar os principais fatores que permitem avaliá-la. Os resultados desses estudos revelam que as empresas com menos acidentes apresentam uma maturidade da cultura de segurança mais avançada. Estas culturas são caracterizadas por fatores como, por exemplo, o comprometimento da direção da empresa, o envolvimento dos empregados e a existência de uma boa comunicação sobre segurança (SILVA; LIMA, 2004).

A abordagem integrada das questões de segurança do trabalho, ambiente e cultura representa na atualidade um grande desafio para melhorar os ambientes de trabalho e reduzir acidentes. Por outro lado, um sistema de produção, qualquer que seja ele, não é sustentável quando o ambiente em que os trabalhadores exercem suas atividades não é seguro e saudável, cause mortes, mutilações e doenças da força de trabalho.

Para obter uma sadia qualidade de vida, o homem necessita conviver em um ambiente ecologicamente equilibrado, sendo que uma das unidades principais desse conjunto é o ambiente do trabalho, no qual o homem passa a maior parte do seu dia útil. O ambiente de trabalho está inserido no ambiente geral, de modo que é impossível atingir um ambiente equilibrado e sustentável ignorando o ambiente de trabalho, nem se pode alcançar qualidade de vida sem ter qualidade no trabalho (OLIVEIRA, 1998).

Embora seja um tema de relevância, estudos sobre cultura de segurança estão restritos em países da Europa, não existem estudos empíricos no Brasil, e não existem modelos validados para identificar seu estágio de maturidade (GULDENMUND, 2000; HUDSON, 2007; LIMA; SILVA, 2005). Segundo Fleming (2001), o conceito de maturidade de cultura de segurança é novo, portanto, é importante explorar seu potencial com a finalidade de melhorar a segurança do trabalho nas organizações.

O objetivo do estudo apresentado neste artigo foi desenvolver um modelo para identificar o estágio de maturidade da cultura de segurança em organizações. Conhecendo o estágio de maturidade da cultura de segurança, os gerentes da organização poderão priorizar esforços e recursos para as áreas que necessitam de melhorias para desenvolver uma cultura de segurança. Portanto, constitui-se este modelo em importante instrumento de Sistema de Gestão da Segurança no Trabalho.

\section{Cultura de segurança: conceitos e impactos na gestão de segurança no trabalho}

O termo cultura de segurança foi conceituado pela primeira vez no relatório técnico sobre o acidente na usina nuclear de Chernobyl na Ucrânia, na década de 1980, como sendo o

[...] conjunto de características e atitudes das organizações e dos indivíduos, que garante que a segurança de uma planta nuclear, pela sua importância, terá a maior prioridade [...] (SILVA, 2003, p. 34).

A partir de então, a indústria nuclear reconheceu a importância da cultura de segurança nas suas instalações e incentivou os operadores de usinas nucleares a avaliá-la. O termo rapidamente ganhou o dicionário do gerenciamento de segurança e o conceito foi utilizado como um substantivo tema em relatórios oficiais de desastres e grandes acidentes. (GLENDON; STANTON, 2000; FLIN et al., 2000; MEARNS; WHITAKER; FLIN, 2003; REASON, 1997).

Após o aparecimento do termo, muitos estudos foram realizados com o objetivo de conceituar e mensurar cultura de segurança, mas não há consenso sobre o tema entre os pesquisadores. Para Guldenmund (2000), embora cultura de segurança seja um importante conceito, não existem consensos sobre seus antecedentes, o seu conteúdo e as suas consequências nos últimos vinte anos. Além disso, existe uma lacuna de modelos que relacione o conceito de cultura de segurança com gerenciamento de risco ou a eficiência dos programas de segurança. Para Reason (1997), cultura de segurança é um termo muito usado, mas poucos concordam sobre seu preciso significado ou como pode ser mensurada. Seguindo esta mesma linha de pensamento, Choudhry, Fang e Mohamed (2007), baseados em uma ampla revisão de literatura de pesquisas publicadas sobre o tema desde 1998, afirmam que, embora o termo cultura de segurança tenha sido largamente usado por muitos anos, o seu conceito não é claro. Segundo estes pesquisadores, a definição dada pelo relatório do acidente de Chernobyl, deixou o significado do termo cultura de segurança aberto para interpretações e sem definir como avaliá-la.

Alguns pesquisadores consideram a cultura de segurança uma particularidade da cultura organizacional. Para estes pesquisadores, a cultura de segurança existe na organização quando a cultura organizacional prioriza a segurança do trabalho ou possui aspectos que a impactam. Entre estes pesquisadores, estão Glendon e Stanton (2000) e Silva e Lima (2004), para quem, a cultura de segurança tem origem na cultura organizacional e tem definição semelhante a esta, ou seja, cultura de segurança é um conjunto de crenças, valores e normas partilhados pelos membros de uma organização que constituem os pressupostos básicos para a segurança do trabalho. Guldenmund (2000) define cultura de segurança como os aspectos da cultura organizacional que impactam 
as atitudes e o comportamento dos membros da organização relativa à segurança do trabalho. Luz (2003) considera que cultura organizacional influencia as atitudes e o comportamento dos indivíduos e dos grupos dentro das organizações, consequentemente, influencia as atitudes e o comportamento destes com relação à segurança do trabalho. Para Hopkins (2006), a cultura organizacional existente na organização impacta a segurança do trabalho, sendo importante entender como esse impacto acontece, com o objetivo de promover intervenções na cultura organizacional, quando necessário, para que segurança do trabalho seja uma prioridade.

Outros pesquisadores definiram cultura de segurança independente do conceito de cultura organizacional. Cooper $(1998,2000)$ definiu cultura de segurança como o resultado das interações dinâmicas entre três aspectos: 1) as percepções e atitudes; 2) o comportamento e ações; e 3) o Sistema de Gestão da Segurança do Trabalho (SGST) da organização. As interações entre estes aspectos podem variar em intensidade e no tempo, dependendo da situação. Por exemplo, pode levar tempo para as mudanças no SGST influenciarem no comportamento e nas atitudes dos membros da organização.

As atitudes e percepções são como as pessoas sentem a organização e estão relacionadas com o individuo; os comportamentos e as ações são o que as pessoas fazem na organização e estão relacionadas ao trabalho; e o SGST é constituído pelas políticas, procedimentos, sistemas de controle, fluxo de informações, etc. e está relacionado à organização. As atitudes e percepções não são fatores observáveis, pois se encontram no campo subjetivo do indivíduo, enquanto que o comportamento e ações e o SGST são aspectos objetivos possíveis de serem observados. Como estes aspectos podem ser mensurados diretamente, é possível também mensurar a cultura de segurança de forma significativa em diferentes estágios organizacionais. A Figura 1 representa esquematicamente as interações entre estes três aspectos presentes na cultura de segurança.

Richter e Koch (2004) definem cultura de segurança como as experiências vividas pelos membros da

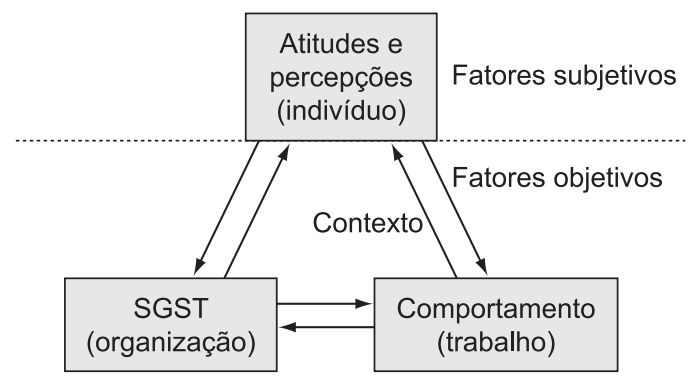

Figura 1. Modelo de interações recíprocas de cultura de segurança. Fonte: Cooper (2000). organização e os significados e as interpretações destas experiências, expressos em parte de forma simbólica, que servem como guia para as ações dos empregados frente aos riscos, aos acidentes e à prevenção. Segundo estes pesquisadores, a cultura de segurança é formada por pessoas e suas relações sociais dentro e fora das organizações e deve ser entendida em um contexto específico que pode mudar dependendo das condições materiais e das relações sociais desenvolvidas. Para eles, a cultura de segurança não é integrada ou única, ou seja, podem existir diferentes culturas em diferentes departamentos ou setores de uma mesma organização. Além disso, durante o processo de mudança, a cultura de segurança pode torna-se ambígua, apresentando características de diferentes estágios de maturidade.

Cox e Cheyne (2000) valorizam o conceito de cultura de segurança porque os recentes estudos sobre o tema revelam, para os gerentes e pesquisadores dessa área, que o conhecimento e o desenvolvimento de uma apropriada cultura de segurança são importantes e podem ser usados como um veículo para promover melhoria da estrutura organizacional para a segurança do trabalho.

Segundo Weick e Sutcliffe (2001), a cultura de segurança ajuda a criar uma cultura sempre atenta ao inesperado, que é uma característica das organizações de alta confiabilidade, como aviação e indústria nuclear, nas quais o sucesso na área de segurança é estar sempre atento ao imprevisto e acreditar que os acidentes sempre estão para acontecer.

Segundo Garcia, Boix e Canosa (2004), o envolvimento dos gerentes parece ser determinante para o desenvolvimento da cultura de segurança, pois consegue envolver os empregados e melhorar sua percepção e suas atitudes nas questões relativas à segurança do trabalho.

Além de pesquisadores, instituições que atuam na área de segurança também apresentaram seu conceito e considerações sobre cultura de segurança. A definição de cultura de segurança dada pela Health and Safety Commission (HSC) da Advisory Committee on the Safety of Nuclear Installations é uma das mais citadas na literatura e considerada por muitos pesquisadores (REASON, 1997; WEICK; SUTCLIFFE, 2001) como a mais competente. Nesta definição se encontram os termos valores, atitudes, percepção, competências (aspectos psicológicos), padrão de comportamento (aspectos relacionados ao trabalho) e programas de segurança do trabalho (aspectos relacionados à organização), que estão presentes na definição de Cooper (2000), aproximando muito as duas definições. De acordo com a definição da HSC:

A cultura de segurança de uma organização é o produto dos valores, atitudes, percepção, competências e padrão de comportamento de indivíduos e grupos que determinam o 
comprometimento, o estilo e a proficiência do gerenciamento da segurança do trabalho da organização. Organizações com culturas de segurança positivas são caracterizadas pela comunicação fundada na confiança mútua, pela percepção compartilhada da importância da segurança e pela confiança na eficácia das medidas preventivas. (REASON, 1997, p.194).

Destaca-se dessa definição a importância da comunicação para uma cultura de segurança positiva, além da confiança dos empregados nas medidas preventivas adotadas. É importante salientar da definição acima, que o sucesso do gerenciamento da segurança do trabalho é determinado pelas percepções, valores, competência e padrão de comportamento dos indivíduos e grupos da organização.

A Agência Internacional de Energia Atômica AIEA (1991) ressalta a importância das atitudes e percepções para a efetividade da cultura de segurança, que, embora sejam aspectos intangíveis, influenciam as manifestações tangíveis, como o comportamento e SGST, que são indicadores da cultura de segurança. Ainda segundo AIEA (AGÊECIA..., 1991), a cultura de segurança tem dois componentes. $\mathrm{O}$ primeiro é o comprometimento dos gerentes e a estrutura necessária dentro da organização para a segurança do trabalho. O segundo é a atitude e a percepção dos empregados em todos os níveis da organização com relação ao envolvimento dos gerentes e a estrutura da organização.

A Organização Internacional do Trabalho - OIT (2004) extrapola a definição de cultura de segurança de uma organização para o conceito de cultura de segurança de um país como um todo. Segundo a OIT, a cultura de segurança de um país é o respeito ao direito à segurança no ambiente de trabalho, devendo os governantes, os empregadores e os trabalhadores participarem ativamente na defesa deste direito e o princípio da prevenção deve ser acordado como mais alta prioridade. Para a OIT, o país que tiver esta cultura pode permeá-la para as organizações. Depreende-se deste conceito da OIT que a cultura do país exerce papel importante para que as organizações tenham uma cultura de segurança.

Estudos sobre cultura de segurança não têm tido apenas o objetivo de conceituá-la ou mensurá-la, mas também de mostrar sua influência ou relação com acidentes do trabalho, pois existe nos últimos anos uma tendência de mudar a ênfase de fatores individuais como causas de acidentes de trabalho para fatores organizacionais, como a cultura de segurança (COX; CHEYNE, 2000; HARRISSON; LEGENDRE, 2003; MEARNS; WHITAKER; FLIN, 2003; NEAL; GRIFFIN; HART, 2000). Vuuren (2000) classificou os fatores organizacionais que influenciam os acidentes de trabalho em: fatores relativos à estrutura da organização; fatores relativos às estratégias e objetivos; e fatores relacionados à cultura de segurança. Segundo ele, é considerável o impacto da cultura de segurança nas causas de acidente e no gerenciamento do risco.

Segundo a AIEA (2002b), pesquisas sobre acidentes em organizações indicam que problemas com a cultura de segurança são causas frequentes, por isto, atualmente o foco da indústria está no esforço para melhorar a cultura de segurança, que pode ser realizado em todos os estágios da vida da organização.

Embora não exista consenso com relação ao conceito de cultura de segurança, há similaridade e convergência entre eles. Muitos aspectos presentes nos diferentes conceitos de cultura de segurança apresentados acima são comuns e podem ser agrupados da seguinte forma:

- Aspectos relacionados ao indivíduo: são os valores, crenças, atitudes e percepção dos indivíduos com relação à gestão da segurança do trabalho. Estes aspectos da cultura de segurança refletem o que a organização é.

- Aspectos relacionados ao trabalho: é o comportamento e ações do indivíduo com relação ao sistema de gestão da segurança do trabalho e aos riscos presentes no ambiente de trabalho.

- Aspectos relacionados à organização: são as práticas e estrutura da organização para dar suporte ao indivíduo e ao sistema de gestão da segurança do trabalho. Estes aspectos da cultura de segurança refletem o que a organização tem.

Para a construção do instrumento de identificação de maturidade de cultura de segurança apresentado neste artigo, foi adotado o conceito proposto por Cooper (2000) e considerado que a cultura de segurança pode ser modificada atuando nos aspectos organizacionais, que se relacionará com os outros dois aspectos (indivíduo e trabalho) e, consequentemente, modificará a cultura de segurança, conforme as concepções de Reason (1997) e Hopkins (2005) e o modelo de interações recíprocas de cultura de segurança proposto por Cooper (2000).

\section{Maturidade de cultura de segurança}

O conceito de maturidade foi inicialmente desenvolvido nos Estados Unidos pelo Software Engineering Institute (SEI), na década de 1980, para atender a uma necessidade do governo federal americano de avaliar a capacidade das empresas contratadas para desenvolver sistemas de informática. Naquela década, devido à grande demanda por informatização, muitas empresas de engenharia de software eram contratadas sem a capacidade necessária, acarretando prejuízos de tempo e dinheiro. O modelo previa os seguintes estágios de maturidade 
das empresas para desenvolver os software e prestar posterior assistência: inicial (initial), o repetível (repeatable), o definido (defined), o gerenciado (managed) e o otimizável (optimizing). A capacidade das empresas era classificada de acordo com seu estágio de maturidade (PAULK et al., 1993). Posteriormente, o conceito de maturidade foi adaptado para ser usado em outros ramos de atividade como, por exemplo, gerenciamento de projetos, recursos humanos e qualidade (FLEMING, 2001).

Fleming (2001) utilizou o conceito de maturidade desenvolvido pelo SEI, para criar um modelo de maturidade para a cultura de segurança, com o objetivo de ajudar as empresas de petróleo do Reino Unido a identificar a maturidade de sua cultura e quais ações necessárias para melhorá-la. Este modelo tem cinco estágios de maturidade: emergindo (emerging), gerenciando (managing), envolvendo (involving), cooperando (cooperating) e melhorando continuamente (continually), pelos quais a organização progredirá sequencialmente, fortalecendo os pontos fortes e removendo os pontos fracos do estágio anterior. O estágio de maturidade de cultura de segurança é determinado com base no tratamento dado pela organização a dez fatores considerados por Fleming (2001) como importantes para formação da cultura de segurança, que são: comprometimento e visibilidade dos gerentes; comunicação; produção vs. segurança; aprendizagem organizacional; recursos para segurança do trabalho; participação dos empregados; percepção compartilhada dos empregados sobre segurança do trabalho; confiança; treinamento; e relações industriais e satisfação no trabalho. A Figura 2 mostra o modelo de Fleming (2001) com os seus cinco estágios de maturidade de cultura de segurança.

Fleming (2001) alerta que o seu modelo somente é aplicável em organizações que atendam aos seguintes critérios:

- Tenha um adequado Sistema de Gestão da Segurança do Trabalho.

- A maioria dos acidentes do trabalho não é causada por falhas técnicas.

- Atenda às leis e normas sobre segurança do trabalho.

- A segurança do trabalho é dirigida para evitar acidentes.

A AIEA (AGÊNCIA..., 2002a) constatou que existem três estágios de evolução de cultura de segurança em usina nuclear. No primeiro estágio, a segurança do trabalho é dirigida principalmente pela obediência às regras e regulamentos e é vista como um tema de responsabilidade da área técnica, as melhorias são obtidas por meio de salvaguardas de

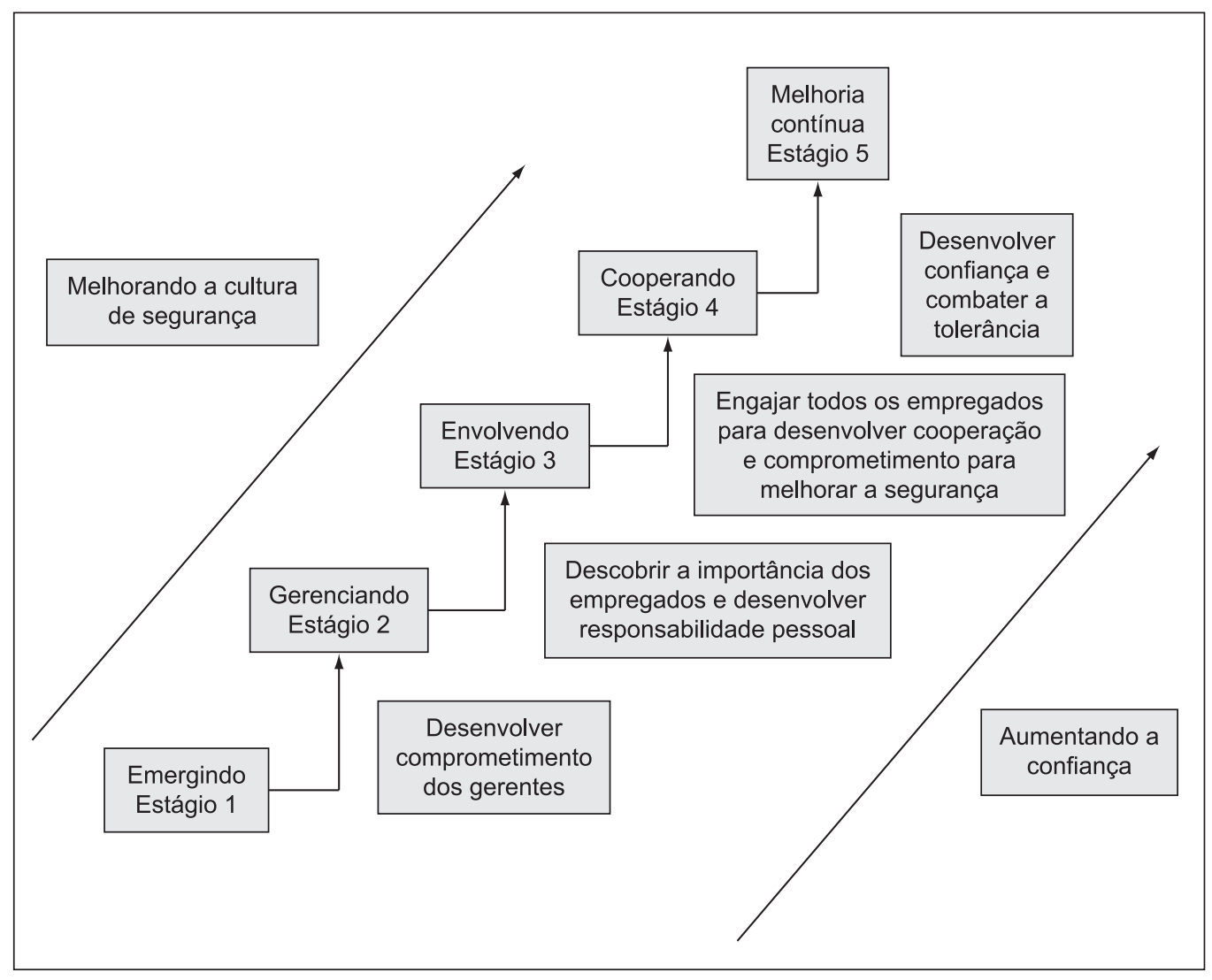

Figura 2. Modelo de maturidade de cultura de segurança proposto por Fleming. Fonte: Fleming (2001). 
engenharia e introdução de procedimentos de controle de riscos. Os empregados tendem a acreditar que a responsabilidade pela área de segurança do trabalho é dos gerentes e em grande parte é imposta por eles.

No segundo estágio, o bom desempenho da segurança do trabalho torna-se um objetivo da organização e é dirigida em termos de objetivos e metas. A organização desenvolverá sua visão e missão com seus valores e objetivos, estabelecendo processos e procedimentos para atingi-los. Os empregados começarão a perceber que o trabalho está mais bem planejado. Entretanto, neste estágio, ainda existe frequentemente imposição por parte da gerência, pouco envolvimento dos empregados e a segurança do trabalho é administrada e monitorada por profissionais da área.

No terceiro estágio, a segurança do trabalho é vista como um processo, que pode ser melhorado continuamente e que todos podem contribuir. É o estágio ideal da cultura de segurança e, para atingi-lo, é necessário um processo contínuo, requer visão e valores totalmente compartilhados com os membros da organização e grande parte deles deve estar comprometido e envolvido pessoal e ativamente na segurança do trabalho. Além disso, as contratadas e os fornecedores também devem estar totalmente envolvidos. O tema segurança do trabalho está integrado na organização. As condições precárias de trabalho e práticas que colocam em risco a segurança são inaceitáveis e são abertamente desafiadas.

Para Westrum $(1993,2004)$, um dos fatores mais importante para a segurança é a informação, pois a falha no fluxo de informação está presente em muitos grandes acidentes. Ele observou que a informação flui bem em algumas organizações, mas, em outras, se acumula e emperra, por razões políticas ou por barreiras burocráticas, e que a qualidade do fluxo de informação não inclui somente o quanto dela flui de A para B, mas a relevância, a oportunidade e a conveniência da informação para o receptor. Com base na maneira com que o fluxo de informações é tratado na organização, ele criou três estágios de cultura:

- Cultura patológica (pathological culture) - a informação é usada como recurso pessoal para ser utilizada como força política no trabalho. A informação não flui, é segurada ou usada como vantagem pessoal dentro da organização.

- Cultura burocrática (bureaucratic culture) - a informação flui por canais ou procedimentos formais. Esta forma de fluir a informação é com frequência insuficiente em momentos de crise.

- Cultura construtiva (generative culture) - a informação flui para a pessoa certa, no momento certo e da forma correta.
Hudson (2001) propôs um modelo de maturidade de cultura de segurança baseado nos três estágios de cultura criados por Westrum (1993). Para criar o seu modelo, ele adicionou dois estágios, o reativo (reacitve) e o proativo (proactive), atendendo a uma sugestão de Reason (1997) de estender os três estágios do modelo de Westrum (1993), e trocou o nome do estágio burocrático (bureaucratic) para calculativo (calculative), por achar que os profissionais da segurança do trabalho assimilariam melhor este termo, pois consideram o termo burocrático pejorativo. No modelo de Hudson (2001), a cultura de segurança evolui de um estágio inicial, o patológico (pathological), até um estágio final ideal, o construtivo (generative). A Figura 3 mostra o modelo de maturidade de Hudson (2001).

Cada estágio de maturidade de cultura de segurança do modelo Hudson (2001) é descrito abaixo:

- Estágio patológico (pathological stage) - neste estágio não há ações na área de segurança do trabalho na organização. O máximo que procura fazer é atender à legislação.

- Estágio reativo (reative stage) - neste estágio as ações da organização da área de saúde e segurança no trabalho são realizadas somente depois de acidentes do trabalho terem acontecido. Ações não são sistemáticas, busca dar respostas aos acidentes do trabalho, procurando remediar a situação.

- Estágio calculativo (calculative stage) - neste estágio a organização tem sistema para gerenciar riscos nos locais de trabalho, mas ainda não tem a visão sistêmica da saúde, segurança e meio ambiente. Ações estão mais voltadas para quantificar os riscos.

- Estágio proativo (proactive stage) - é o desenvolvimento do estágio de transição para o estágio da cultura construtiva. O líder da organização, com base nos valores da organização, conduz as melhorias contínuas para a saúde,

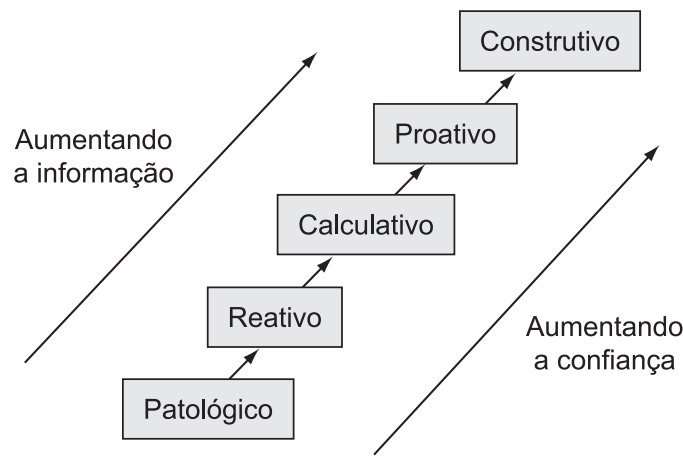

Figura 3. Modelo de maturidade de cultura de segurança proposto por Hudson. Fonte: Hudson (2001). 
segurança e meio ambiente. Procura se antecipar aos problemas antes que eles aconteçam.

- Estágio construtivo (generative stage) - Existe um sistema integrado de saúde, segurança e meio ambiente, no qual a organização se baseia e se orienta para realizar seus negócios. A organização tem as informações necessárias para gerir o sistema de segurança do trabalho, está constantemente tentando melhorar e encontrar as melhores formas de controlar os riscos.

Nos modelos de maturidade de cultura de segurança apresentados, uma organização pode evoluir de um estágio de cultura na qual a segurança do trabalho praticamente não existe até um estágio ideal de segurança. Esta evolução é possível quando se conhece o estágio em que a cultura de segurança se encontra e quais seus pontos fracos, para estabelecer as ações necessárias para que ela passe para o estágio seguinte. Segundo Hopkins (2005), uma organização somente pode se considerar com uma cultura de segurança, em que a segurança do trabalho é um valor, quando ela atingir o último estágio de maturidade. Para ele, não existem culturas de segurança fracas ou fortes, mas estágios de maturidade de cultura ou cultura em evolução.

Estes modelos estão congruentes com o pensamento de Reason (1997), quando ele usa a expressão "construindo uma cultura de segurança" (engineering a safety culture), para mostrar que a construção de uma cultura de segurança é possível, principalmente mudando as práticas da organização com relação à segurança do trabalho; mudando práticas mudam-se os valores. Desde que uma cultura nacional se desenvolve muitas vezes fora dos valores compartilhados pela sociedade, a cultura organizacional e a cultura de segurança em particular podem também ser formadas principalmente pelas práticas compartilhadas pelos membros da organização.

Muitas das ações para atingir uma efetiva cultura de segurança estão mais no campo das técnicas gerencias do que em qualquer outro, considerando as condições em que as pessoas trabalham (REASON, 1997).

A cultura de segurança pode ser socialmente construída pela identificação dos fatores essenciais para sua formação e com ações planejadas para atingi-la. É possível que um grande e grave acidente possa levar a transformações radicais na cultura de segurança, mas estas não serão duradouras. Cultura de segurança não é algo que brota pronto na organização, ela emerge gradualmente com a persistência e com bem sucedidas práticas e aplicação de medidas pés no chão. Atingir uma cultura de segurança é um processo de aprendizagem coletiva, interação entre os membros da organização, compartilhamento de pensamentos e gerenciamento comprometido (REASON, 1997).

\section{Fatores indicativos da maturidade da cultura de segurança}

A cultura de segurança é avaliada e mensurada por meio de fatores que a caracterizam ou são indicativos da sua maturidade, no entanto, não existe um grupo comum de fatores definidos como padrões ou mais representativos para esta avaliação e mensuramento. Por isto, muitos estudos sobre cultura de segurança têm o objetivo de identificar quais são aqueles mais representativos que possam ser utilizados na sua avaliação ou caracterização (FLIN et al., 2000). Na ausência da definição dos fatores mais representativos para avaliação da cultura de segurança, as pesquisas com o objetivo avaliar a cultura de segurança buscam estes fatores na literatura ou em grupos de estudos ou em entrevistas individuais.

Zohar (1980), que foi pioneiro no estudo de clima de segurança, realizou uma revisão de literatura para identificar quais os melhores fatores que avaliam e caracterizam uma cultura de segurança e encontrou os seguintes: atitudes da gerência para a segurança; influência do comportamento seguro para promoção no trabalho; influência do comportamento seguro sobre o status social; status dos profissionais de segurança na organização; importância e efetividade dos treinamentos de segurança; nível de risco no ambiente de trabalho; efetividade do esforço vs. a promoção da segurança.

Williamson et al. (1997), após revisão de literatura, acharam pouca coincidência de fatores presentes em pesquisas levantadas, mas dois fatores apareceram consistentemente: a atitude dos gerentes e a atitude dos empregados com relação à segurança do trabalho.

Cooper (1998) relaciona os seguintes fatores que favorecem a evolução da cultura de segurança: forte comprometimento do líder com a segurança do trabalho; contato próximo e melhor comunicação entre todos os níveis da organização; maior controle de riscos; uma madura e estável força de trabalho; boa seleção de pessoal e procedimento de promoção justo e transparente; avanço no sistema de reforçar a importância da segurança do trabalho, incluindo relatos de acidentes.

Além das características acima, Cooper (1998) acrescentou como essenciais os fatores: adotar políticas formais de segurança; priorizar a segurança no mesmo nível dos outros objetivos da organização; investigar todos os acidentes e incidentes; auditar regularmente o sistema de segurança para obter informações para o desenvolvimento de ações de melhorias contínuas.

Flin et al. (2000) fizeram uma revisão de literatura procurando identificar quais são os principais fatores que foram utilizados em pesquisas de cultura de segurança. Segundo estes pesquisadores, existe uma proliferação de fatores sendo utilizadas e que poucas pesquisas são replicadas utilizando o mesmo 
conjunto de fatores. Outra situação encontrada é a dificuldade de comparação entre os fatores, não só devido às inconsistências metodológicas, mas também devido às diferenças culturais e de linguagem de países e indústria onde são realizadas estas pesquisas. No entanto, eles concluíram que não existe nenhuma evidência a favor ou contra que haja um conjunto comum de fatores para serem utilizadas em pesquisa de avaliação de cultura de segurança, mas acreditam que devido à multiplicidade, há um movimento na direção de classificar um grupo de fatores fundamentais. Após levantamento realizado na revisão de literatura, os pesquisadores englobaram os fatores encontrados em cinco grupos, que são: a) gerenciamento: está relacionado com as atitudes e comportamento da gerência com a segurança; b) sistema de segurança: engloba muitos diferentes aspectos do sistema de gestão de segurança, tais como comitês de segurança, permissão para trabalho, políticas de segurança e equipamento de segurança; c) risco: inclui percepção do risco no local de trabalho e atitudes frente ao risco e à segurança; d) pressão no trabalho: relativo a ritmo e carga de trabalho; e e) competência: refere-se à qualificação, habilidades e conhecimento do empregado para o trabalho.

Guldenumund $(2000,2007)$ fez uma análise crítica sobre o número de fatores encontrados na literatura para avaliar a cultura de segurança e concluiu que há um número excessivo. Ele observou que fatores relativos aos gerentes aparecem $75 \%$ das vezes e os relativos ao Sistema de Gestão de Segurança do Trabalho aparecem em dois terços dos estudos. Outra constatação, semelhante aos achados de Flin et al. (2000), é que muitas pesquisas não conseguem replicar os fatores encontradas em pesquisas anteriores, até mesmo na mesma organização.

Reason (1997) considera que os fatores cruciais para a formação de uma cultura de segurança são: a informação; um clima organizacional de confiança no qual os empregados se sentem encorajados, até recompensados, a prover informações essenciais sobre a segurança no trabalho; a flexibilidade e a aprendizagem organizacional. A interação destes fatores forma uma cultura informada, essencial para a prevenção dos acidentes organizacionais.

Hudson (2001) acrescentou mais um fator à lista de Reason (1997), que chamou de prudência: a organização e seus membros devem está sempre atentos para os inesperados, mantendo alto grau de vigilância contra acidentes.

Choudhry, Fang e Mohamed (2007) realizaram revisão de literatura e acharam cinco fatores que caracterizam uma cultura de segurança: a) comprometimento dos gerentes com a segurança do trabalho; b) mútua confiança entre gerentes e empregados; c) autonomia para os empregados; d) monitoramento contínuo; e) melhoria da segurança do trabalho.
Ek et al. (2007), para avaliar a cultura de segurança em empresa de controle de tráfego aéreo, utilizaram os seguintes fatores: aprendizagem: que significa coletar, monitorar e analisar informações importantes para aumentar o conhecimento sobre como o trabalho e a segurança estão funcionando; informação: que significa a propensão dos empregados em informar os incidentes e as anormalidades observadas no trabalho; justiça: por parte da organização para avaliar as falhas de forma justa e imparcial, o que contribui para a confiança dos empregados para informar os incidentes e as anormalidades; flexibilidade: considera a habilidade para transformar a organização do trabalho para atingir as mudanças necessárias; comunicação: da organização para os empregados de forma clara e precisa sobre temas relativos à segurança do trabalho; comportamento: relativo às ações dos empregados para segurança do trabalho; atitudes: percepção dos empregados relativa à segurança do trabalho e ao interesse da gerência pelo seu bem-estar; situação no trabalho: relativo à cooperação e ao suporte dado pela organização à segurança no trabalho; e a percepção do risco: relativo à maneira como os empregados veem os riscos presentes no ambiente de trabalho.

A AIEA (AGÊNCIA..., 2002b) encontrou os seguintes fatores que são indicativos da maturidade da cultura de segurança em instalações nucleares: atitudes da organização de contínuo melhoramento: a ausência de contínuo melhoramento impedirá a evolução da aprendizagem organizacional e encoraja a complacência que é prejudicial para o desenvolvimento progressivo da cultura de segurança; efetivo canal de comunicação: a organização que pretende desenvolver e melhorar sua cultura de segurança deve assegurar que as informações são efetivamente comunicadas; comprometimento da gerência: uma boa cultura de segurança não se desenvolverá sem o comprometimento da gerência, por isso, é particularmente importante que o corpo gerencial demonstre comprometimento; sistema efetivo de planejamento: um método sistemático é necessário quando do desenvolvimento da cultura de segurança, a ausência deste método demonstra uma fraca cultura de segurança; adequada fontes de recursos: falta de fontes de recursos é sintoma de fraca cultura de segurança; habilidade e competência: o trabalho tem potencial impacto sobre a segurança somente se for realizado por pessoas qualificadas e competentes; influências externas: as influências podem ser sociais, políticas, econômicas ou legais. Muitas organizações frente a pressões externas podem questionar seu futuro, os empregados, por sua vez, podem se sentir sem esperança no futuro e ficar com moral baixo. Neste estado, os empregados estão menos inclinados a mudar e atender as melhorias.

Pela revisão de literatura apresentada, observa-se que não existe um grupo definido de fatores que são 
utilizados para avaliar, mensurar e caracterizar uma cultura de segurança ou que possa ser indicativo de sua maturidade. No entanto, muitos fatores aparecem frequentemente em diferentes pesquisas, às vezes mudando apenas o nome.

Para selecionar os fatores indicativos da maturidade de cultura de segurança no modelo apresentado neste artigo, foi realizada uma revisão de literatura de 25 estudos, incluindo os apresentados acima, e os cinco fatores mais frequentemente citados foram escolhidos.

A descrição dos cinco fatores selecionados apresentada a seguir foi feita a partir da literatura abaixo mencionada:

- Informação - é confiança dos indivíduos na organização para relatar os erros, os acidentes e os incidentes ocorridos. Aspecto essencial para construir uma cultura informada (REASON, 1997). Incluem também os indicadores que são gerados pela organização para monitorar o desempenho da segurança do trabalho (HUDSON, 2003; AIEA, 2002b).

- Aprendizagem organizacional - é a forma como a organização trata as informações, como é feita a análise dos acidentes e dos incidentes, se são propostas ações de melhoria e se são implementadas e se os empregados são informados sobre estas ações, e se há busca contínua de melhorar os processos visando à segurança do trabalho (AIEA, 2002b; REASON, 1997).

- Envolvimento - é a participação dos empregados nas questões de segurança, como na análise dos acidentes e incidentes que lhe diz respeito, na identificação e análise dos riscos do ambiente de trabalho, nas propostas de ações para melhoria da segurança do trabalho e sua implementação, na elaboração e revisão dos procedimentos relacionados com sua atividade, no planejamento das suas atividades, e a participação em comitês de segurança, encontros de segurança, etc. (CHOUDHRY; FANG; MOHAMED, 2007; GORDON; KIRWAN; PERRIN, 2007).

- Comunicação - é a forma, a conveniência e a oportunidade que é feita à comunicação sobre os temas relativos à segurança do trabalho, e se há um canal aberto de comunicação entre os empregados e superiores hierárquicos. Inclui também se comunicação chega aos empregados, se é compreendida por eles e se a organização monitora a efetividade da comunicação (COOPER, 1998; GLENDON; STANTON, 2000; OLIVE; O'CONNOR; MANNAN, 2006; MEARNS; WHITAKER; FLIN, 2003; WESTRUM, 2004).
- Comprometimento - é evidenciado pela proporção de recursos (tempo, dinheiro, pessoas) e suportes alocados para a gestão da segurança do trabalho, pelos status da segurança do trabalho em relação à produção, pela existência de um Sistema de Gestão da Segurança do Trabalho, em que constam a visão e objetivos da organização, definição de responsabilidades, a política de treinamento e qualificação, procedimentos, recompensas, sanções e auditorias. $\mathrm{O}$ verdadeiro comprometimento significa mais que políticas escritas e mencionar a importância da segurança do trabalho nos discursos, precisa haver coerência entre as palavras e a realidade (DEJOY et al., 2004; FLIN et al., 2000; AIEA, 2002b; OLIVE, O'CONNOR; MANNAN, 2006).

\section{Desenvolvimento do modelo de identificação de estágio de maturidade de cultura de segurança}

O modelo desenvolvido nesta pesquisa foi construído tendo como base o modelo proposto por Hudson (2001), apresentado na Figura 3. Foram realizadas pequenas alterações nesse modelo com o objetivo de torná-lo mais aderente à realidade em que foi realizada a pesquisa, como a troca do nome do estágio calculativo para burocrático, como originalmente proposto por Westrum (1993).

O modelo proposto por Fleming (2001) não foi escolhido como base por que o seu uso somente é relevante em organizações que atendam aos seguintes critérios: a) tenha um adequado Sistema de Gestão da Segurança do Trabalho; b) a maioria dos acidentes não é causada por falhas técnicas; c) atenda às leis e normas sobre segurança no trabalho; e d) segurança do trabalho é dirigida para evitar acidentes, o que restringe sua aplicação no contexto brasileiro, no qual a grande maioria das empresas não atende a esses critérios.

O modelo desenvolvido descreve na sua estrutura como cada um dos cinco fatores selecionados e descritos acima (informação, aprendizagem organizacional, envolvimento, comunicação e comprometimento) é tratado em cada um dos cincos estágios de maturidade da cultura de segurança: patológico, reativo, burocrático, proativo e construtivo (ver APÊNDICE A). Esta descrição foi baseada na literatura (PARKER; LAWRIE; HUDSON, 2006) e na experiência deste pesquisador que trabalha há dez anos como engenheiro de segurança no cargo de Auditor-Fiscal do Trabalho do Ministério do Trabalho e Emprego e trabalhou durante 11 anos como engenheiro em plataformas de petróleo e refinaria da Petrobrás. 
São encontrados no modelo fatores com a mesma descrição em diferentes estágios, como exemplo, o fator aprendizagem organizacional tem alguns itens com a mesma descrição nos estágios proativo e melhoria contínua, isto acontece por não haver uma fronteira definida, na qual termina um estágio e começa o outro.

O estágio de maturidade da cultura de segurança em uma organização será estabelecido pela maneira como ela trata cada um dos cinco fatores, conforme descritos no modelo. Pode ocorrer de um determinado fator estar em diferentes estágios de maturidade de cultura de segurança. Isto está coerente com o conceito de que cultura de segurança não se desenvolve simultaneamente em toda a organização e de que pode levar tempo para as medidas adotadas para melhorá-la possam surtir efeito, ou podem exercer mais efeito em determinadas áreas do que em outras (FLEMING, 2001; COOPER, 2000), situação observada por Hudson e Willekes (2000) na pesquisa realizada em uma companhia de petróleo em Oman na Ásia.

Uma organização somente pode considerar que tem uma cultura de segurança quando atingir integralmente o último estágio de maturidade, no qual a segurança é a mais alta prioridade. Esta concepção desafia a visão de que toda organização tem uma cultura de segurança, mas varia em efetividade. Nesta visão, a organização tem uma cultura de segurança forte quando tem a segurança como alta prioridade e uma cultura de segurança fraca quando não existe prioridade para segurança no trabalho (HOPKINS, 2005; HUDSON et al., 2000).

\section{Conclusão}

Atualmente, os fatores organizacionais, como a cultura de segurança, apontam como principais os fatores relacionados aos acidentes de trabalho. Um Sistema de Gestão da Segurança do Trabalho, que gerencie os riscos e enfatize a cultura de segurança, é um instrumento essencial para melhorar as condições no ambiente de trabalho e reduzir acidentes e doenças ocupacionais. Para ter um Sistema de Gestão da Segurança do Trabalho bem sucedido, é necessário que a organização tenha uma cultura de segurança estabelecida. Assim, o conhecimento do estágio de maturidade da cultura de segurança é condição essencial para adotar as medidas necessárias para o sucesso deste sistema.

Na revisão de literatura apresentada, observa-se que existem modelos de estágios de maturidade de cultura de segurança, mas existe ausência de um modelo que possibilite identificar em que estágio de maturidade se encontra a cultura de segurança de uma organização. O presente trabalho teve o objetivo de desenvolver um modelo que identifique o estágio de maturidade de cultura de segurança, preenchendo esta lacuna existente na literatura e que poderá ser utilizado na gestão de segurança do trabalho das organizações.

O modelo desenvolvido define os seguintes estágios de uma cultura de segurança numa organização: patológico, reativo, burocrático, proativo e melhoria contínua. O estágio é definido pelo modo como a organização trata os seguintes fatores, considerados como essenciais para a cultura de segurança: informação, aprendizagem organizacional, envolvimento, comunicação e comprometimento.

Considera-se que este trabalho contribui não só para o estudo da segurança do trabalho, mas também para o diagnóstico e intervenção nessa área, especificamente pela utilização do modelo desenvolvido para identificar o estágio de maturidade da cultura de segurança, com aplicações para a prevenção de acidentes de trabalho, assim como para enfrentar seus novos desafios e novos contextos.

Os resultados obtidos neste trabalho apresentam algumas consequências para os estudos da segurança do trabalho, especificamente pela utilização do modelo desenvolvido que identifica o estágio de maturidade da cultura de segurança em organizações.

O modelo desenvolvido viabiliza os gerentes e pesquisadores diagnosticarem a cultura de segurança de uma grande empresa ou um conjunto de empresas simultaneamente, quando não há recursos e tempo disponíveis para estudá-las de forma mais aprofundada, pois o modelo é de fácil e rápida aplicação. Com base nesse diagnóstico, eles poderão definir qual a estratégia de intervenção mais adequada para melhorar sua cultura de segurança.

O sucesso de uma intervenção na segurança do trabalho nas organizações depende da capacidade de realizar um bom diagnóstico da sua situação. Assim, recomenda-se que o modelo desenvolvido neste estudo seja validado em trabalhos futuros, para fortalecer suas bases teóricas, e posteriormente ser utilizado como uma importante ferramenta de gestão de segurança nas empresas, contribuindo para o sucesso e o bom desempenho do SGST, que, por sua vez, impactará na segurança das operações, dos trabalhadores e na prevenção de acidentes do trabalho.

\section{Referências}

AGÊNCIA INTERNACIONAL DE ENERGIA ATÔMICA. INSAG-15 - Key practical issues in strengthening safety culture. Vienna, 2002a. 25 p.

AGÊNCIA INTERNACIONAL DE ENERGIA ATÔMICA. Safety séries n ${ }^{\circ} \mathbf{7 5}$ - INSAG - 4 - Safety Culture. Viena, $1991.30 \mathrm{p}$.

AGÊNCIA INTERNACIONAL DE ENERGIA ATÔMICA. Self-assessment of safety culture in nuclear installations: higlights and good practices. Viena, 2002b. 29 p.

CHOUDHRY, R. M.; FAG, D.; MOHAMED, S. The nature of safety culture: a survey of the state-of-the-art. Safety Science, n. 45, p. 903-1012, 2007. 
COOPER, D. Improving safety culture: a practical guide. Londres: Wiley, 1998. 318 p.

COOPER, D. Towards a model of safety culture. Safety Science, n. 36, p. 111-136, 2000.

COX, S. J.; CHEYNE, A. J. T. Assessing safety in offshore environments. Safety Science, n. 34, p. 215-257, 2000.

DEJOY, D. M. et al. Creating safer workplaces: assessing the determinantes and role of safety climate. Journal of Safety Research, n. 35, p. 81-90, 2004.

EK, A. et al. Safety cultura in Swedish air traffic control. Safety Science, n. 45, p. 791-811, 2007.

FLEMING, M. Safety culture maturity model. Health and Safety Executive. Colegate, Norwich, 2001.

FLIN, R. et al. Measuring climate: identifying the common features. Safety Science, n. 34, p. 177-192, 2000.

GARCIA, A. M.; BOIX, P.; CANOSA, C. Why do workers behave unsafety at work? Determinants of safe work pratices in industrial workers. Occupational and Environmental Medicine, n. 61, p. 239-246, 2004.

GLENDON, A. I.; STANTON, N. A. Perspectives on safety culture. Safety Science, n. 34, p. 193-214, 2000.

GORDON, R.; KIRWAN, B.; PERRIN, E. Measuring safety culture in a research and development centre: A comparison of two methods in the Air Traffic Management domain. Safety Science, n. 45, p. 669-695, 2007.

GULDENMUND, F.W. The nature of safety culture: a review of theory and research. Safety Science, n. 34, p. 193-214, 2000.

GULDENMUND, F.W. The use of questionanaires in safety culture research - an evaluation. Safety Science, n. 45, p. 723-743, 2007.

HARRISSON, D.; LEGENDRE, C. Technological innovations, organizational change and workplace accident prevention. Safety Science, n. 41, p. 319-338, 2003.

HOPKINS, A. Safety, Culture and Risk: the organizational causes of disasters. Sydney: CCH, 2005. 171 p.

HOPKINS, A. Study organizational cultures and their effects on safety. Safety Science, n. 44, p. 875-889, 2006.

HUDSON, P. Applying the lessons of high risk industries to health care. Quality \& Safety in Health Care, n. 12, p. I7-I12, 2003.

HUDSON, P. Aviation safety culture. Safeskies, p. 1-23, 2001.

HUDSON, P. et al. The hearts and minds project: creating intrinsinc motivation for HSE. In: SPE INTERNATIONAL CONFERENCE ON HEALTH, SAFETY, AND THE ENVIRONMENT IN OIL AND GAS EXPLORATION AND PRODUCTION, 10., 2000, Stavanger, Noruega. Anais...Richardson/Texas: SPE, 2000. p. 1-8.

HUDSON, P. Implementing a safety culture in a major multi-national. Safety Science, n. 45, p. 697-722, 2007.

HUDSON, P.; WILLEKES, F. C. The hearts and minds project in an operating company: developing tools to measure cultural factors. In: SPE INTERNATIONAL CONFERENCE ON HEALTH, SAFETY, AND THE ENVIRONMENT IN OIL AND GAS EXPLORATION AND PRODUCTION, 10., 2000, Stavanger, Noruega. Anais... Richardson/Texas: SPE, 2000. p. 1-7.

LIMA, M. L.; SILVA, S. Avaliar a cultura de segurança - instrumentos desenvolvidos para as empresas portuguesas. In: SOARES, C. G.; TEIXEIRA, A. P.; ANTÃ̃O, P. (Org.). Análise e gestão de riscos. Lisboa: Ed. Salamandra, 2005. p. 149-158.
LUZ, R. Gestão do clima organizacional. Rio de Janeiro: Editora QUALITYMARK, 2003. 143 p.

MEARNS, K.; WHITAKER, S. M.; FLIN, R. Safety climate, safety management practice and safety perfornance in offshore environments. Safety Science, n. 41, p. 641-680, 2003.

NEAL, A.; GRIFFIN, M. A.; HART, P. M. The impacto of organizacional climate on safety climate and individual behavior. Safety Science, n. 34, p. 99-19, 2000.

OLIVE, C.; O'CONNOR, T. M.; MANNAN, M. S. Relationship of safety culture and process safety. Journal of Hazardous of Materials, n. 130, p. 133-140, 2006.

OLIVEIRA, S. G. Proteção jurídica à saúde do trabalhador. 2. ed. São Paulo: Ed. LTr, 1998. 421 p.

ORGANIZAÇÃO INTERNACIONAL DO TRABALHO. Safe work and safety culture. The ILO report for world day for safety and health at work 2004. Genebra, 2004.

PARKER, D.; LAWRIE, M.; HUDSON, P. A framework for understand the development of organizational safety culture. Safety Science, n. 44, p. 551-562, 2006.

PAULK, M. C. et al. Capability maturity model for software. Version 1.1. Pensylvania: Software Engineering Institute, 1993. 65 p.

REASON, J. Managing the risks of organizational accidents. Inglaterra: Ashgate Publishing Limited, 1997. 252 p.

RICHTER, A.; KOCH, C. Integration, differentiation and ambiguity in safety cultures. Safety Science, n. 42, p. 703-722, 2004.

SILVA, C. A. S.; LIMA, M. L. Culturas de segurança e aprendizagem com acidentes. In: VALA, J.; GARRIDO, M.; ALCOBIA, P. (Org.). Percursos da investigação em psicologia social e organizacional. Lisboa: Ed. Colibri, 2004. vol. I, p. 257-270.

SILVA, S. C. A. Culturas de segurança e prevenção de acidentes de trabalho numa abordagem psicossocial: valores organizacionais declarados e em uso. 2003. 385 f. Tese (Doutorado em Psicologia Social e Organizacional)-Departamento de Psicologia Social e das Organizações-Instituto Superior de Ciências do Trabalho e da Empresa, Lisboa, 2003.

VUUREN, W. V. Cultural influences on risks and risk management: six cases studies. Safety Science, n. 35, p. 31-45, 2000.

WEICK, K. E.; SUTCLIFFE, K. M. Managing the unexpected. Assuring high performance in an age of complexity. São Francisco/Estados Unidos: JOSSEYBASS, 2001. 208 p.

WESTRUM, R. A typology of organizational cultures. Quality \& Safety in Health Care, n. 13, p. 22-27, 2004.

WESTRUM, R. Cultures with requisite imagination. In: WISE, J. A.; HOPKIN, V. D.; STAGER, P. (Org.). Verification and validation of complex systems: human factors issues. New York: Springer-Verlag, 1993. p. 413-427.

WILLIAMSON, A. M. et al. The development of a measure of safety climate: the role of safety perceptions and attitudes. Safety Science, v. 25, n. 1-3, p. 15-27, 1997.

ZOHAR, D. Safety climate in industrial organizations: theorical and applied implications. Journal of Applied Psychology, n. 1, p. 96-102, 1980.Apêndice A - Modelo desenvolvido. 


\section{Apêndice A - Modelo desenvolvido}

Quadro 1. O fator informação nos diferentes estágios de maturidade de cultura de segurança.

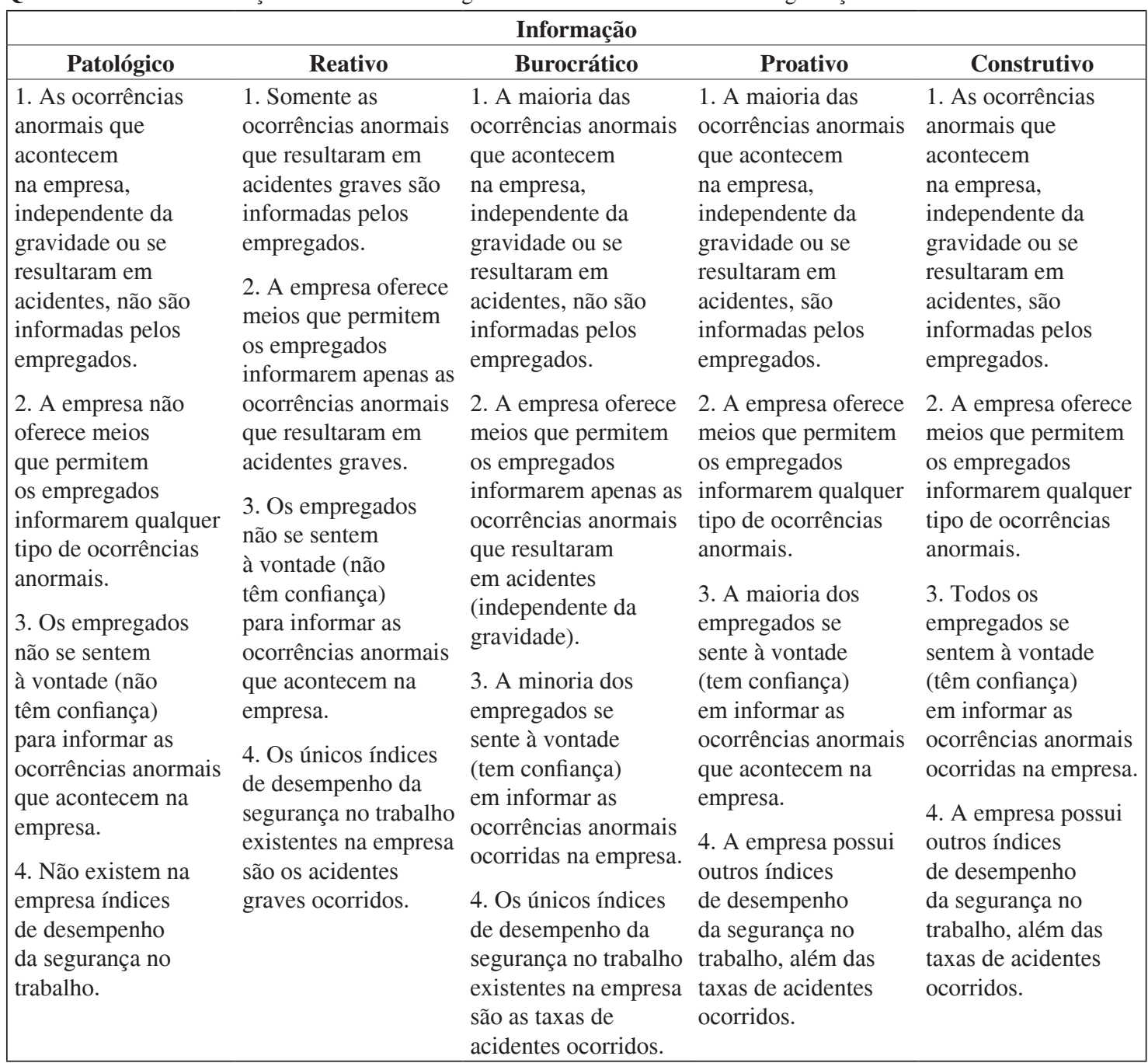


Quadro 2. O fator aprendizagem organizacional nos diferentes estágios de maturidade de cultura de segurança.

\begin{tabular}{|c|c|c|c|c|}
\hline \multicolumn{5}{|c|}{ Aprendizagem organizacional } \\
\hline Patológico & Reativo & Burocrático & Proativo & Construtivo \\
\hline $\begin{array}{l}\text { 1. A empresa não } \\
\text { faz análise das } \\
\text { ocorrências anormais. } \\
\text { 2. A análise das } \\
\text { ocorrências anormais } \\
\text { feita pela empresa se } \\
\text { restringe a identificar } \\
\text { os culpados pelas } \\
\text { ocorrências. } \\
\text { 3. A empresa não } \\
\text { faz melhorias } \\
\text { em segurança no } \\
\text { trabalho. } \\
\text { 4. A empresa não } \\
\text { informa o resultado } \\
\text { das análises das } \\
\text { ocorrências anormais } \\
\text { para os empregados. }\end{array}$ & $\begin{array}{l}\text { 1. A empresa faz } \\
\text { análise apenas das } \\
\text { ocorrências anormais } \\
\text { que resultaram em } \\
\text { acidentes graves. } \\
\text { 2. A análise das } \\
\text { ocorrências anormais } \\
\text { feita pela empresa se } \\
\text { restringe a identificar } \\
\text { as causas imediatas } \\
\text { das ocorrências. } \\
\text { 3. A empresa faz } \\
\text { melhorias em } \\
\text { segurança no trabalho } \\
\text { apenas quando } \\
\text { ocorrem acidentes } \\
\text { graves. } \\
\text { 4. A empresa informa } \\
\text { o resultado da análise } \\
\text { das ocorrências } \\
\text { anormais apenas } \\
\text { aos empregados } \\
\text { envolvidos com a } \\
\text { ocorrência. }\end{array}$ & $\begin{array}{l}\text { 1. A empresa faz } \\
\text { análise apenas das } \\
\text { ocorrências anormais } \\
\text { que resultaram } \\
\text { em acidentes } \\
\text { (independente da } \\
\text { gravidade). } \\
\text { 2. A análise das } \\
\text { ocorrências anormais } \\
\text { feita pela empresa se } \\
\text { restringe a identificar } \\
\text { falhas das máquinas, } \\
\text { dos equipamentos, } \\
\text { da manutenção e dos } \\
\text { empregados. } \\
\text { 3. A empresa faz } \\
\text { melhorias em } \\
\text { segurança no trabalho } \\
\text { apenas nos setores } \\
\text { em que há riscos de } \\
\text { acidentes. } \\
\text { 4. A empresa informa } \\
\text { o resultado da análise } \\
\text { das ocorrências } \\
\text { anormais apenas aos } \\
\text { empregados do setor } \\
\text { envolvido com a } \\
\text { ocorrência. }\end{array}$ & $\begin{array}{l}\text { 1. A empresa faz } \\
\text { análise da maior } \\
\text { parte das ocorrências } \\
\text { anormais. } \\
\text { 2. A análise das } \\
\text { ocorrências anormais } \\
\text { feita pela empresa } \\
\text { abrange a empresa } \\
\text { como um todo, tais } \\
\text { como os processos } \\
\text { de trabalho, decisões } \\
\text { gerenciais que } \\
\text { influenciaram na } \\
\text { ocorrência, os } \\
\text { procedimentos } \\
\text { de trabalho, a } \\
\text { contribuição das } \\
\text { máquinas e das } \\
\text { pessoas para a } \\
\text { ocorrência. } \\
\text { 3. A empresa faz } \\
\text { continuamente } \\
\text { melhorias em } \\
\text { segurança do } \\
\text { trabalho. } \\
\text { 4. A empresa informa } \\
\text { apenas o resultado } \\
\text { das análises dos } \\
\text { acidentes graves para } \\
\text { todos os empregados. }\end{array}$ & $\begin{array}{l}\text { 1. A empresa faz } \\
\text { análise de todas as } \\
\text { ocorrências anormais, } \\
\text { independente da } \\
\text { gravidade ou se } \\
\text { resultaram em } \\
\text { acidentes. } \\
\text { 2. A análise das } \\
\text { ocorrências anormais } \\
\text { feita pela empresa } \\
\text { abrange a empresa } \\
\text { como um todo, tais } \\
\text { como os processos } \\
\text { de trabalho, decisões } \\
\text { gerenciais que } \\
\text { influenciaram na } \\
\text { ocorrência, os } \\
\text { procedimentos } \\
\text { de trabalho, a } \\
\text { contribuição das } \\
\text { máquinas e das } \\
\text { pessoas para a } \\
\text { ocorrência. } \\
\text { 3. A empresa faz } \\
\text { continuamente } \\
\text { melhorias em } \\
\text { segurança do } \\
\text { trabalho. } \\
\text { 4. A empresa } \\
\text { informa os resultados } \\
\text { das análises das } \\
\text { ocorrências anormais } \\
\text { para todos os } \\
\text { empregados, para } \\
\text { compartilhar as lições } \\
\text { aprendidas. }\end{array}$ \\
\hline
\end{tabular}


Quadro 3. O fator comunicação nos diferentes estágios de maturidade de cultura de segurança.

\begin{tabular}{|c|c|c|c|c|}
\hline \multicolumn{5}{|c|}{ Comunicação } \\
\hline Patológico & Reativo & Burocrático & Proativo & Construtivo \\
\hline $\begin{array}{l}\text { 1. As notícias sobre } \\
\text { segurança no trabalho } \\
\text { não são divulgadas } \\
\text { pela empresa. } \\
\text { 2. Não existe um } \\
\text { canal aberto de } \\
\text { comunicação entre } \\
\text { a empresa e os } \\
\text { empregados para } \\
\text { falar sobre segurança } \\
\text { no trabalho. } \\
\text { 3. A comunicação } \\
\text { sobre segurança no } \\
\text { trabalho feita pela } \\
\text { empresa não chega } \\
\text { aos empregados. }\end{array}$ & $\begin{array}{l}\text { 1. As notícias } \\
\text { sobre segurança no } \\
\text { trabalho somente } \\
\text { são divulgadas pela } \\
\text { empresa quando } \\
\text { ocorrem acidentes } \\
\text { graves. } \\
\text { 2. Existe um } \\
\text { canal aberto de } \\
\text { comunicação entre } \\
\text { a empresa e os } \\
\text { empregados para } \\
\text { falar sobre segurança } \\
\text { no trabalho apenas } \\
\text { quando acontecem } \\
\text { acidentes graves. } \\
\text { 3. A comunicação } \\
\text { sobre segurança no } \\
\text { trabalho feita pela } \\
\text { empresa não chega } \\
\text { aos empregados. }\end{array}$ & $\begin{array}{l}\text { 1. As notícias sobre } \\
\text { segurança no trabalho } \\
\text { divulgadas pela } \\
\text { empresa limitam- } \\
\text { se às previstas } \\
\text { em normas de } \\
\text { segurança, como, por } \\
\text { exemplo, sobre uso } \\
\text { do Equipamento de } \\
\text { Proteção Individual } \\
\text { (EPI) e a Comissão } \\
\text { Interna de Prevenção } \\
\text { de Acidentes (CIPA). } \\
\text { 2. O canal de } \\
\text { comunicação entre } \\
\text { a empresa e os } \\
\text { empregados para } \\
\text { falar sobre segurança } \\
\text { no trabalho é formal } \\
\text { (com base em normas } \\
\text { e procedimentos } \\
\text { da empresa, como, } \\
\text { por exemplo, na } \\
\text { Comissão Interna } \\
\text { de Prevenção de } \\
\text { Acidentes (CIPA) e } \\
\text { em reuniões formais } \\
\text { de trabalho). } \\
\text { 3. A comunicação } \\
\text { sobre segurança } \\
\text { no trabalho feita } \\
\text { pela empresa chega } \\
\text { à minoria dos } \\
\text { empregados. }\end{array}$ & $\begin{array}{l}\text { 1. As notícias sobre } \\
\text { segurança no trabalho } \\
\text { divulgadas pela } \\
\text { empresa são diversas, } \\
\text { tais como o uso do } \\
\text { Equipamento de } \\
\text { Proteção Individual } \\
\text { (EPI), palestras sobre } \\
\text { segurança, índices de } \\
\text { acidentes, resultados } \\
\text { de análises de } \\
\text { ocorrências anormais, } \\
\text { proteção à saúde, } \\
\text { melhorias realizadas } \\
\text { em segurança no } \\
\text { trabalho, entre outros. } \\
\text { 2. Existe um } \\
\text { canal aberto de } \\
\text { comunicação entre } \\
\text { a empresa e os } \\
\text { empregados para } \\
\text { falar sobre segurança } \\
\text { no trabalho. } \\
\text { 3. A comunicação } \\
\text { sobre segurança } \\
\text { no trabalho feita } \\
\text { pela empresa chega } \\
\text { à maioria dos } \\
\text { empregados. }\end{array}$ & $\begin{array}{l}\text { 1. As notícias sobre } \\
\text { segurança no trabalho } \\
\text { divulgadas pela } \\
\text { empresa são diversas, } \\
\text { tais como o uso do } \\
\text { Equipamento de } \\
\text { Proteção Individual } \\
\text { (EPI), palestras sobre } \\
\text { segurança, índices de } \\
\text { acidentes, resultados } \\
\text { de análises de } \\
\text { ocorrências anormais, } \\
\text { proteção à saúde, } \\
\text { melhorias realizadas } \\
\text { em segurança no } \\
\text { trabalho, entre outros. } \\
\text { 2. Existe um } \\
\text { canal aberto de } \\
\text { comunicação entre } \\
\text { a empresa e os } \\
\text { empregados para } \\
\text { falar sobre segurança } \\
\text { no trabalho. } \\
\text { 3. A comunicação } \\
\text { sobre segurança no } \\
\text { trabalho feita pela } \\
\text { empresa chega a } \\
\text { todos os empregados. }\end{array}$ \\
\hline
\end{tabular}


Quadro 4. O fator comprometimento nos diferentes estágios de maturidade de cultura de segurança.

\begin{tabular}{|c|c|c|c|c|}
\hline \multicolumn{5}{|c|}{ Comprometimento } \\
\hline Patológico & Reativo & Burocrático & Proativo & Construtivo \\
\hline $\begin{array}{l}\text { 1. Não existe } \\
\text { na empresa } \\
\text { planejamento } \\
\text { em segurança } \\
\text { no trabalho. } \\
\text { 2. A empresa } \\
\text { não faz } \\
\text { auditorias em } \\
\text { segurança no } \\
\text { trabalho. } \\
\text { 3. A empresa } \\
\text { não faz } \\
\text { investimentos } \\
\text { em segurança } \\
\text { no trabalho. } \\
\text { 4. A empresa } \\
\text { não realiza } \\
\text { treinamento em } \\
\text { segurança no } \\
\text { trabalho. } \\
\text { 5. A empresa } \\
\text { não possui } \\
\text { equipe para } \\
\text { apoio à } \\
\text { segurança no } \\
\text { trabalho. } \\
\text { 6. A segurança } \\
\text { no trabalho não } \\
\text { é prioridade na } \\
\text { empresa. } \\
\text { terceirizadas } \\
\text { sem } \\
\text { preocupação } \\
\text { com a } \\
\text { segurança no } \\
\text { procedimentos } \\
\text { em segurança } \\
\text { no trabalho na } \\
\text { empresa. } \\
\end{array}$ & $\begin{array}{l}\text { 1. O planejamento } \\
\text { da empresa para a } \\
\text { segurança no trabalho } \\
\text { é voltado apenas para } \\
\text { corrigir o que deu } \\
\text { errado no passado. } \\
\text { 2. A empresa faz } \\
\text { auditorias em } \\
\text { segurança no trabalho } \\
\text { apenas depois que } \\
\text { acidentes graves } \\
\text { ocorrem. } \\
\text { 3. A empresa faz } \\
\text { investimentos em } \\
\text { segurança no trabalho } \\
\text { apenas depois que } \\
\text { acidentes graves } \\
\text { ocorrem. } \\
\text { 4. A empresa } \\
\text { realiza treinamento } \\
\text { em segurança no } \\
\text { trabalho apenas } \\
\text { após a ocorrência de } \\
\text { acidentes graves. } \\
\text { 5. A empresa } \\
\text { possui uma equipe } \\
\text { pequena para apoio } \\
\text { à segurança no } \\
\text { trabalho. }\end{array}$ & $\begin{array}{l}\text { 1. O planejamento } \\
\text { da empresa para a } \\
\text { segurança no trabalho } \\
\text { é voltado apenas para a } \\
\text { identificação e análise } \\
\text { dos riscos existentes no } \\
\text { ambiente de trabalho. } \\
\text { 2. A empresa faz } \\
\text { auditorias em segurança } \\
\text { no trabalho apenas nas } \\
\text { áreas em que existem } \\
\text { riscos de acidentes. } \\
\text { 3. A empresa faz } \\
\text { investimento em } \\
\text { segurança no trabalho } \\
\text { apenas nas áreas em } \\
\text { que existem riscos de } \\
\text { acidentes. } \\
\text { 4. A empresa } \\
\text { realiza treinamentos } \\
\text { em segurança no } \\
\text { trabalho apenas } \\
\text { para os empregados } \\
\text { que trabalham em } \\
\text { ambientes em que } \\
\text { existem riscos de } \\
\text { acidentes. } \\
\text { 5. A empresa possui } \\
\text { uma equipe com } \\
\text { dimensão adequada } \\
\text { para apoio à segurança } \\
\text { no trabalho. }\end{array}$ & $\begin{array}{l}\text { 1. O planejamento } \\
\text { da empresa para a } \\
\text { segurança no trabalho } \\
\text { não é integrado com } \\
\text { o planejamento das } \\
\text { outras áreas da empresa } \\
\text { (como, por exemplo, a } \\
\text { área de produção). } \\
\text { 2. A empresa faz } \\
\text { auditorias em } \\
\text { segurança do trabalho } \\
\text { em todos seus setores. } \\
\text { 3. A empresa investe } \\
\text { continuamente em } \\
\text { segurança no trabalho } \\
\text { em todos os seus } \\
\text { setores. } \\
\text { 4. A empresa realiza } \\
\text { continuamente } \\
\text { treinamento em } \\
\text { segurança no trabalho } \\
\text { para todos os } \\
\text { empregados. }\end{array}$ & $\begin{array}{l}\text { 2. A empresa faz } \\
\text { auditorias em } \\
\text { segurança do trabalho } \\
\text { em todos seus setores. } \\
\text { 3. A empresa investe } \\
\text { continuamente em } \\
\text { segurança no trabalho } \\
\text { em todos os seus } \\
\text { setores. } \\
\text { 4. A empresa realiza } \\
\text { continuamente } \\
\text { treinamento em } \\
\text { segurança no trabalho } \\
\text { para todos os } \\
\text { empregados. } \\
\text { 5. A empresa não } \\
\text { possui uma equipe } \\
\text { para apoio à segurança } \\
\text { no trabalho por que a } \\
\text { responsabilidade pela } \\
\text { área é distribuída por } \\
\text { toda a empresa. } \\
\text { 6. A segurança no } \\
\text { trabalho é a maior } \\
\text { prioridade na empresa. } \\
\text { 7. Os procedimentos } \\
\text { Tristema de Gestão } \\
\text { em segurança no } \\
\text { trabalho da empresa } \\
\text { apresentam as } \\
\text { melhores práticas para } \\
\text { executar a tarefa e } \\
\text { são constantemente } \\
\text { revisados para adequá- } \\
\text { los à realidade do } \\
\text { trabalho. } \\
\text { 8. A empresa } \\
\text { tensidera as } \\
\text { integrante de seu }\end{array}$ \\
\hline
\end{tabular}


Quadro 5. O fator envolvimento nos diferentes estágios de maturidade de cultura de segurança.

\begin{tabular}{|c|c|c|c|c|}
\hline \multicolumn{5}{|c|}{ Envolvimento } \\
\hline Patológico & Reativo & Burocrático & Proativo & Construtivo \\
\hline $\begin{array}{l}\text { 1. Os empregados } \\
\text { não participam } \\
\text { das questões sobre } \\
\text { segurança no trabalho } \\
\text { da empresa. } \\
\text { 2. Os empregados } \\
\text { não se interessam } \\
\text { em participar das } \\
\text { questões sobre } \\
\text { segurança no trabalho } \\
\text { na empresa. }\end{array}$ & $\begin{array}{l}\text { 1. Os empregados } \\
\text { participam das } \\
\text { questões sobre } \\
\text { segurança no trabalho } \\
\text { apenas quando } \\
\text { ocorrem acidentes } \\
\text { graves na empresa. } \\
\text { 2. Os empregados } \\
\text { se interessam em } \\
\text { participar das } \\
\text { questões sobre } \\
\text { segurança no trabalho } \\
\text { apenas quando } \\
\text { ocorrem acidentes } \\
\text { graves na empresa. }\end{array}$ & $\begin{array}{l}\text { 1. A minoria dos } \\
\text { empregados participa } \\
\text { das questões sobre } \\
\text { segurança no trabalho } \\
\text { da empresa. } \\
\text { 2. A minoria } \\
\text { dos empregados } \\
\text { se interessa em } \\
\text { participar das } \\
\text { questões sobre } \\
\text { segurança no trabalho } \\
\text { na empresa. }\end{array}$ & $\begin{array}{l}\text { 1. A maioria dos } \\
\text { empregados participa } \\
\text { das questões sobre } \\
\text { segurança no trabalho } \\
\text { da empresa. } \\
\text { 2. A maioria } \\
\text { dos empregados } \\
\text { se interessa em } \\
\text { participar das } \\
\text { questões sobre } \\
\text { segurança no trabalho } \\
\text { na empresa. }\end{array}$ & $\begin{array}{l}\text { 1. Todos os } \\
\text { empregados } \\
\text { participam das } \\
\text { questões sobre } \\
\text { segurança no trabalho } \\
\text { da empresa. } \\
\text { 2. Todos os } \\
\text { empregados se } \\
\text { interessam em } \\
\text { participar das } \\
\text { questões sobre } \\
\text { segurança no trabalho } \\
\text { na empresa. }\end{array}$ \\
\hline
\end{tabular}

